\title{
AVALIAÇÃO DA DURABILIDADE DE ARGAMASSAS INORGÂNICAS COM ADIÇÃO DE POZOLANA
}

\author{
MOTA, JOÃO \\ Professor Doutor \\ Instituto Federal de Pernambuco \\ Pernambuco; Brasil \\ joaomota@,recife.ifpe.edu.br \\ MORAES, JOÃO \\ Graduando em engenharia civil \\ Instituto Federal de Pernambuco \\ Pernambuco; Brasil \\ Joaovictor.o.moraes@gmail.com
}

\author{
SANTOS, ANDRÉ \\ Mestre em engenharia civil \\ Instituto Federal de Pernambuco \\ Pernambuco; Brasil \\ andresantos@recife.ifpe.edu.br
}

\author{
LIMA, MIÉLIX \\ Químico industrial e Mestrando \\ Instituto Tecnológico de Pernambuco \\ Pernambuco; Brasil \\ mielixlima@recife.ifpe.edu.br
}

\author{
SANTANA, PEDRO \\ Engenheiro Civil \\ CSENG \\ Pernambuco; Brasil \\ pedro@campossantana.com.br
}

\section{RESUMO}

Tecnologias concernentes às argamassas vêm tomando atenção de diversos pesquisadores, tendo em vista sua reduzida durabilidade em diversos casos. Portanto, compósitos cimentícios de argamassas para fachada e alvenaria estrutural, devem conter adições minerais com o cunho de incrementar as propriedades mecânicas e as relacionadas com a durabilidade, fundamentalmente devido às reações da sílica da pozolana com o hidróxido de cálcio da matriz cimentícia, produzindo C-S-H [silicato de cálcio hidratado (molécula responsável pela resistência da matriz - fenômeno químico)]; além de contribuir com o refinamento dos poros - efeito Filer (fenômeno físico). O presente trabalho busca avaliar a influência da metacaulim na durabilidade de argamassas, donde foram especificadas duas proporcionalidades (traços) no programa experimental, sendo o traço "forte" [(1:0,5:4,5:1,5) - cimento, cal, areia e relação água/cimento] e o traço "médio" [(1:1:6:1,5) - cimento, cal, areia e relação água/cimento]. Foi utilizado metacaulim nos teores $(0 \%, 8 \%, 15 \%)$ com duas formas de adicionamento em relação ao cimento: (i) por substituição de parte do cimento; (ii) simples adição pura em relação ao cimento. As propriedades mecânicas (compressão axial, tração por compressão diametral, módulo de elasticidade e velocidade de propagação da onda ultrassônica) e as relacionadas à durabilidade (câmaras de carbonatação e cloretos) mostraram que os teores de $15 \%$ na forma de adição pura, indicaram incrementos mais significativos nas propriedades.

Palavras-chave: durabilidade de argamassas; metacaulim; carbonatação e cloretos.

\begin{abstract}
Technologies concerning mortars have been taking attention from several researchers, in view of their reduced durability in several cases. Therefore, cementitic composites of mortars for façade and structural masonry, should contain mineral additions with the nature of increasing mechanical properties and those related to durability, mainly due to the reactions of the silica of pozolan with calcium hydroxide of the cementitious matrix, producing C-S- $\mathrm{H}$ [hydrated calcium silicate (molecule responsible for matrix resistance - chemical phenomenon)]; in addition to contributing to the refinement of pores - Filer effect (physical phenomenon). The present work seeks to evaluate the influence of metakalin on the durability of mortars, from which two proportionalities (traits) were specified in the experimental program, and the "strong" trait [(1:0,5:4,5:1,5) - cement, lime, sand and water/cement ratio] and the "mean" trait [(1:1:6:1,5) cement, lime, sand and water/cement ratio]. Metakalin was used in the contents $(0 \%, 8 \%, 15 \%)$ with two forms of addition in relation to cement: (i) by replacing part of the cement; (ii) simple pure addition to cement. The mechanical properties (axial compression, traction by diametrictraral compression, modulus of elasticity and speed of ultrasonic wave propagation) and those related to durability (carbonation chambers and chlorides) showed that the contents of $15 \%$ in the form of pure addition indicated more significant increases in the properties.
\end{abstract}

Keywords: mortar durability; metakaolin; carbonation and chlorides. 


\section{INTRODUÇÃO}

Pode-se dizer que o principal aspecto das manifestações patológicas em revestimentos externos, é a reduzida extensão de aderência na interface base/argamassas (elevada porosidade na interface). Essa deficiência conduz a mitigação da aderência das argamassas e, ou, das placas cerâmicas (MOTA et al., 2010). A Figura 1 apresenta três situações que mostram manifestações patológicas com na deficiência de aderência, a saber: "a" (destacamento de revestimento em casario no Recife antigo), "b" (descolamento de revestimento cerâmico externo em edifício de Recife) e "c" (descolamento na fachada do edifício em Florianópolis).

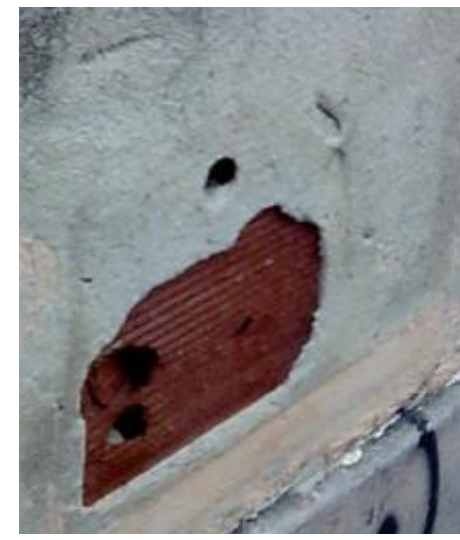

(a)

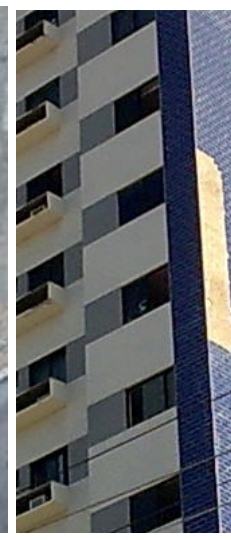

(b)

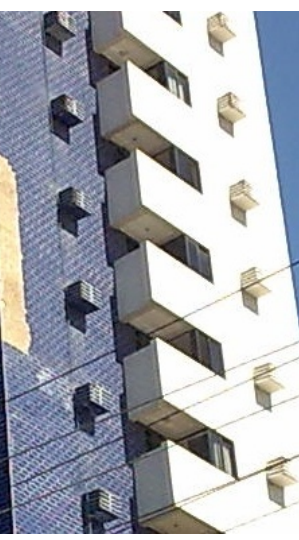

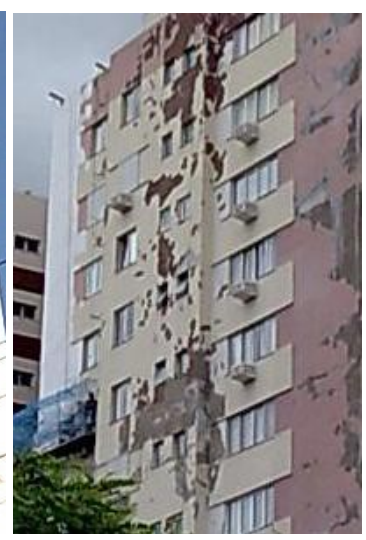

(c)

Figura 1 - Manifestações patológicas concernentes a revestimentos de fachada

Estudos realizados com microscopia eletrônica de varredura em material da região da interface de uma argamassa cimentícia aderida a um substrato, mostraram que o povoamento de cálcio nos poros das bases, aumenta a extensão de aderência devido a maior cobertura do substrato pelas partículas finas da cal (CHASE, 1985, SILVA e LIBÓRIO, 2003). Portanto, os laços de C-S-H (silicato de cálcio hidratado) adsorvidos e absorvidos nos substratos, contribui significativamente na aderência, tendo em vista incrementar o intertravamento mecânico (base/argamassa, Figura 2).

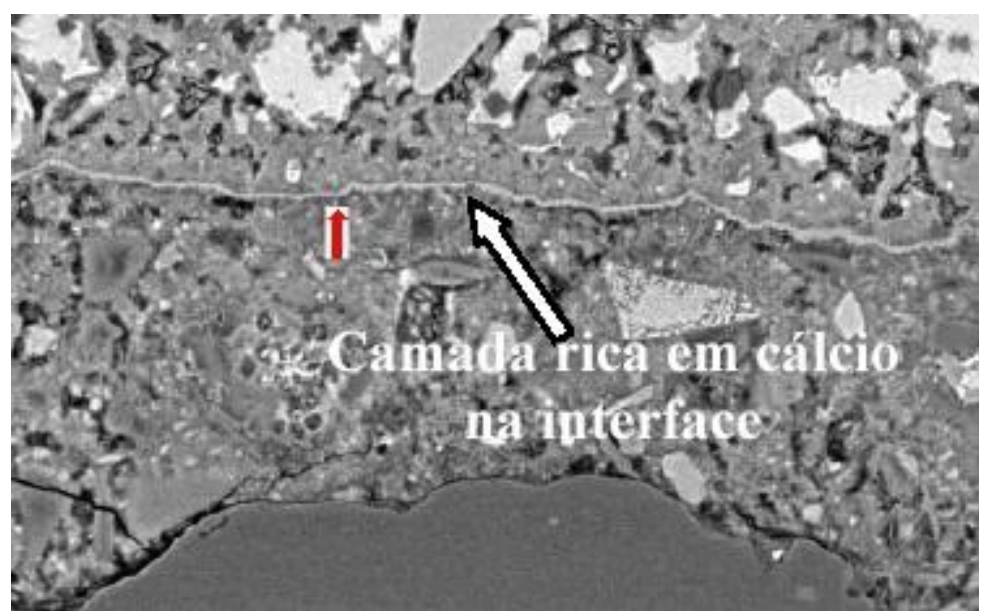

Figura 2 - Ampliação da região indicada pelo círculo na micrografia (SILVA e LIBÓRIO, 2003)

Concernente à ação das adições minerais na interface argamassa/substrato, pode-se explanar que o benefício elevado advém do efeito proporcionado pela reação entre a sílica da pozolana e o hidróxido de cálcio produzido na hidratação do cimento, formando o C-S-H, composto responsável pela resistência da matriz cimentícia, concomitantemente com o próprio efeito filer, reduzindo a relação água/cimento na interface (MOTA, 2015). Portanto, verifica-se que, dentre as principais vantagens das adições pozolânicas em argamassas com dosagens adequadas são: maior trabalhabilidade; menor exsudação e permeabilidade; elevação da resistência mecânica a longas idades; maior proteção em meios agressivos e meios expansivos dentre outros. A Figura 3 apresenta de forma esquemática a região de aderência, na interface, de argamassa com adição de sílica na base. 


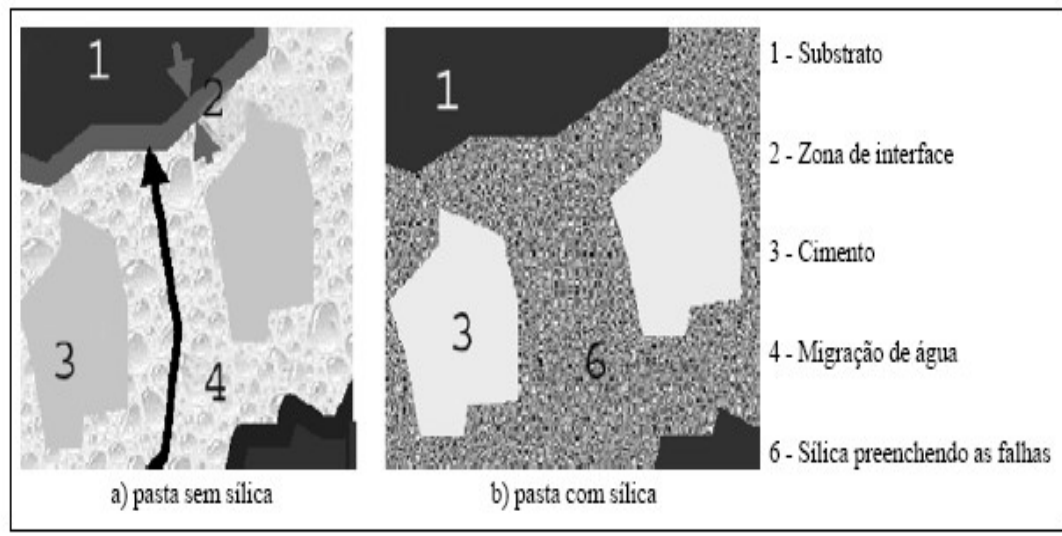

Figura 3 - Representação esquemática da zona de interface pasta/substrato (SILVA e LIBÓRIO, 2003)

De acordo com a norma NBR 12653:2015 a pozolana é um material silicoso ou silicoaluminoso que possui pouca atividade aglomerante, porém, quando finamente dividido e em presença de água, reagem com o hidróxido de cálcio à temperatura ambiente formando compostos com propriedades aglomerantes. A metacaulim, por sua vez, é uma pozolana artificial constituído de material amorfo e estrutura desordenada, obtido por processo industrial de ativação térmica entre $600^{\circ} \mathrm{C}$ a $850^{\circ} \mathrm{C}$ de argilas caulinitas e caulim (MEDINA, 2011). Vale salientar que, a temperatura de cura da mistura com metacaulim tem grande influência na velocidade de reação, já que influencia à cinética, na formação e a estabilidade dos produtos de hidratação.

Mota et al. (2016) enfatiza a contribuição da pozolana metacaulim na durabilidade das argamassas, por mitigarem ações deletérias como cloretos em ambientes marinhos, sulfatos, dióxido de carbono e outros microclima de áreas urbanas. Além disso, o autor ainda afirma que a durabilidade é derivada da densificação e refinamento dos poros, devido a reações pozolânicas. A estrutura dos poros é essencial para a vida útil das argamassas e concretos, fundamentalmente quando estão conectados, tendo em vista que pode mitigar ou não a entrada de agentes nocivos, elevando a durabilidade do material (METHA, 2008).

Conforme Lacerda e Helene (2005), o módulo de elasticidade, parâmetro significativo na qualidade de argamassas e concretos, possui uma elevação em até $15 \%$ nas argamassas com adição de metacaulim, tornando a matriz mais densa e rígida. Outro parâmetro que retrata bem a estrutura dos poros na argamassa é o índice de vazios, onde em pesquisa experimental realizado por Helene e Lacerda (2004) foi verificado que amostras com 8\% de adição de metacaulim, apresentaram menor índice de vazios em diferentes idades e diferentes traços, quando comparadas as de referência (sem a adição de metacaulim), Figura 4.

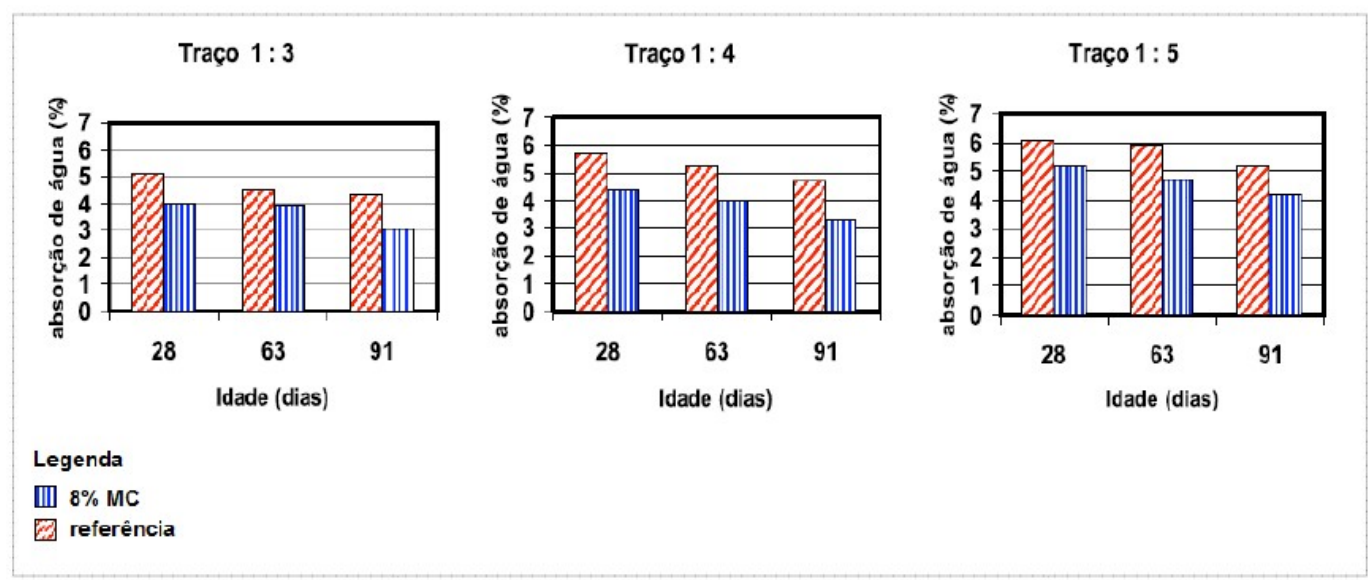

Figura 4: Índice de vazios aos 28, 63 e 91 dias (HELENE e LACERDA, 2004)

Através do trabalho realizado por Helene e Medeiros (2004), avaliou-se o desempenho da adição metacaulim HP na resistividade de compósitos cimentícios, verificando que todas as amostras com adição, apresentaram valores extremamente acima das amotsras de referência (R), indicando ação inibidora relevante para corrosão de armaduras. 


\begin{tabular}{|c|c|c|c|}
\hline & 28 dias & 63 dias & 91 dias \\
\hline traço & & Resistividade (k $\Omega . c m)$ & \\
\hline \multicolumn{4}{|c|}{$8 \%$ de substituiçăo de cimento por adição } \\
\hline $1: 3,0 \mathbf{R}$ & 30,7 & 36,5 & 37,7 \\
\hline $1: 3,0 \mathrm{M}$ & 72,4 & 92,4 & 136,8 \\
\hline $1: 4,0 \mathbf{R}$ & 30,5 & 34,8 & 34,3 \\
\hline $1: 4,0 \mathrm{M}$ & 71,3 & 76,7 & 81,3 \\
\hline $1: 5,0 \mathbf{R}$ & 26,7 & 31,5 & 44,7 \\
\hline $1: 5,0 \mathrm{M}$ & 62,2 & 71,2 & 74,5 \\
\hline \multicolumn{4}{|c|}{$10 \%$ de substituição de cimento por adiçāo } \\
\hline $1: 2,8 \mathbf{R}$ & 95 & 106 & 115 \\
\hline $1: 2,8 \mathrm{M}$ & 313 & 315 & 317 \\
\hline $1: 3,6 \mathbf{R}$ & 70 & 87 & 102 \\
\hline $1: 3,6 \mathrm{M}$ & 182 & 191 & 197 \\
\hline $1: 4,4 \mathrm{R}$ & 31 & 57 & 79 \\
\hline $1: 4,4 \mathrm{M}$ & 139 & 152 & 167 \\
\hline
\end{tabular}

Figura 5: Resistividade elétrica para concretos com "slump" de 80 mm (HELENE e MEDEIROS, 2004)

Diante dos diversos benefícios promovidos pela matecaulim, é válido constatar o trabalho de Rocha (2005) apud Silva et al. (2013), donde evidenciam o baixo impacto ambiental que a produção da pozolana metacaulim ocasiona, devido o seu processo de calcinação emitir apenas vapor de água, além disso, o beneficiamento do caulim gera areia quartzosa, material largamente utilizado na construção civil.

Não obstante, vale sublinhar que, algumas pesquisas com adições minerais (elevados teores) em compósitos cimentícios, apresenta redução importante do $\mathrm{pH}$, objeto do consumo excessivo da Portlandita (" $\mathrm{X}$ " moléculas de hidróxido de cálcio gerado na hidratação do cimento) pela sílica amorfa (pozolana). Portanto, esse fenômeno quando ocorre, é desfavorável, e, propicia a quebra da camada passivadora das armaduras nos concretos contribuindo possivelmente para aceleração da corrosão.

O presente estudo tem como objetivo analisar a influência de diferentes teores de metacaulim na durabilidade de argamassas.

\section{METODOLOGIA}

\subsection{Materiais}

Os materiais utilizados para a confecção dos corpos de prova foram o cimento Portland CP II Z - 32, cal tipo CH-I, pozolana metacaulim HP ULTRA e areia natural média.

A Cal cálcica CH-I foi de fabricação carbomil, de acordo com a Tabela 1.

Tabela 1 - Características da Cal

\begin{tabular}{|c|c|c|c|}
\hline \multicolumn{3}{|c|}{ Ensaio } & Cal Hidratada CH I (Cálcica) \\
\hline \multirow{4}{*}{ 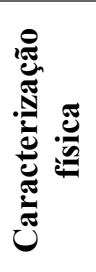 } & \multirow{2}{*}{ Finura (\% retida) } & \#30 $(0,600 \mathrm{~mm})$ & 0,3 \\
\hline & & $\# 200(0,075 \mathrm{~mm})$ & 1,8 \\
\hline & \multicolumn{2}{|c|}{ Densidade aparente $\left(\mathrm{g} / \mathrm{cm}^{3}\right)$} & 0,5 \\
\hline & \multicolumn{2}{|l|}{ Umidade (\%) } & 1,2 \\
\hline \multirow{7}{*}{ 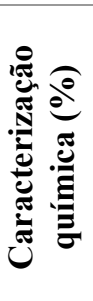 } & \multicolumn{2}{|c|}{ Anidrido Carbônico $-\mathrm{CO}_{2}$} & 2,2 \\
\hline & \multicolumn{2}{|c|}{ Anidrido Sulfúrico - $\mathrm{SO}_{3}$} & 0,05 \\
\hline & \multicolumn{2}{|c|}{ Perda ao fogo } & 24,1 \\
\hline & \multicolumn{2}{|c|}{ Sílica e resíduo insolúvel } & 0,8 \\
\hline & \multicolumn{2}{|c|}{ Óxido não hidratado } & 7,3 \\
\hline & \multicolumn{2}{|c|}{$\mathrm{CaO}$} & 73,7 \\
\hline & \multicolumn{2}{|c|}{$\mathrm{MgO}$ não hidratado } & 0,7 \\
\hline
\end{tabular}


A pozolana metacaulim HP ULTRA, sílica e alumina na fase amorfa (vítrea) apresentam características na Tabela 2.

Tabela 2 - Características químicas da metacaulim HP (\%)

\begin{tabular}{c|c}
\hline $\mathrm{SiO}_{2}$ & 51 \\
\hline $\mathrm{Al}_{2} \mathrm{O}_{3}$ & 40 \\
\hline $\mathrm{Fe}_{2} \mathrm{O}_{3}$ & 2 \\
\hline $\mathrm{CaO} / \mathrm{MgO} / \mathrm{SO}_{3}$ & - \\
\hline $\mathrm{Na}_{2} \mathrm{O}$ & 0,08 \\
\hline $\mathrm{K}_{2} \mathrm{O}$ & 0,18 \\
\hline $\mathrm{Umidade}$ & 0,6 \\
\hline $\mathrm{Perda}$ ao Fogo & 2, \\
\hline $\mathrm{Equivalente} \mathrm{alcalino}_{\mathrm{SiO}}+\mathrm{Al}_{2} \mathrm{O}_{3}+\mathrm{Fe}_{2} \mathrm{O}_{3}$ & 0,2 \\
\hline Odor $/ \mathrm{pH}$ & 94 \\
\hline
\end{tabular}

A distribuição granulométrica do metacaulim HP pode ser determinada por difração de raio laser. Todavia, esse método que determina o tamanho das partículas não é adequado para o metacaulim, visto as partículas lamelares e não esféricas, remetendo para o BET a forma adequada (HELENE e MEDEIROS, 2004). A Tabela 3 mostra algumas características físicas da pozolana metacaulim HP ULTRA, determinado pelo método BET.

Tabela 3 - Características físicas do metacaulim do Brasil

\begin{tabular}{c|c}
\hline Diâmetro médio das partículas & $12,4 \mu \mathrm{m}$ \\
\hline Densidade de massa específica & $2.650 \mathrm{~kg} / \mathrm{m}^{3}$ \\
\hline Massa unitária & $600 \mathrm{~kg} / \mathrm{m}^{3}$ \\
\hline Área de superfície específica - método BET & $327.000 \mathrm{~cm}^{2} / \mathrm{g}$ \\
\hline Resultado de atividade pozolânica a \\
$90 \pm 5^{\circ} \mathrm{C}$ & $771,2 \mathrm{mg} \mathrm{CaO} / \mathrm{g}$ amostra \\
\hline Estado físico / Forma & Sólido / pó seco \\
\hline
\end{tabular}

O agregado miúdo utilizado foi uma areia natural de natureza quartzosa com características e granulometria descritas na tabela 4 .

Tabela 4 - Características da areia natural

\begin{tabular}{c|c}
\hline Dim. Máximo característico (mm) - NBR NM 248 & 4,8 \\
\hline Módulo de finura - NBR NM 248 & 2,5 \\
\hline Massa unitária (g/cm $)$ - NBR NM 45 & 1,4 \\
\hline Massa específica (g/cm $)$ - NBR NM 45 & 2,6 \\
\hline Inchamento - NBR 6467 & 1,2 \\
\hline Teor de material pulverulento (\%) - NBR 7219 & 2,1 \\
\hline Umidade (\%) - NBR 6467 & 3,4 \\
\hline Matéria orgânica - NBR NM 49 & Clara \\
\hline Coeficiente de uniformidade - método de Allen-Hazen & 3 \\
\hline
\end{tabular}




\subsection{Métodos}

Os ensaios programados foram: - resistência à compressão (NBR 13279:2005); - módulo de elasticidade dinâmico (NBR 15630:2009); - velocidade de propagação da onda ultrassônica (NBR 8802:2019); e método acelerado de envelhecimento para avaliação de desempenho: - carbonatação (CPC-18, RILEM, 1988); - cloretos solúveis (ASTM C 1152:2012); a caracterização e durabilidade de corpos de prova das argamassas estudadas, em CP's moldados em forma cilíndrica de $5 \mathrm{~cm} \times 10 \mathrm{~cm}$. Em todos os casos observou-se a matriz de consistência 200 +/- 20 mm determinado na mesa de flow table.

A partir dos dois traços (volume) estudados [1:1:6:1,5 e 1:0,5:4,5:1,5 - (cimento, cal, areia e relação água/cimento)], avaliaram-se os teores de $8 \%$ e $15 \%$ de metacaulim: - sem adição; - com adição por substituição em massa de parte do cimento; - adição pura (em massa, sem retirar parte do cimento), conforme Tabela 5. Portanto, o teor de aglomerantes encontra-se sempre constante para os grupos de famílias compilados.

Tabela 5 - Amostras analisadas nos ensaios de durabilidade

\begin{tabular}{c|c}
\hline Traço médio $-1: 1: 6: 1,5$ & Traço forte $-1: 0,5: 4,5: 1,5$ \\
\hline $0 \%$ Metacaulim & $0 \%$ Metacaulim \\
\hline 8\% Substituição de parte do cimento & $8 \%$ Substituição de parte do cimento \\
\hline $15 \%$ Substituição de parte do cimento & $15 \%$ Substituição de parte do cimento \\
\hline $8 \%$ Adição pura em relação ao cimento & $8 \%$ Adição pura em relação ao cimento \\
\hline $15 \%$ Adição em relação ao cimento & $15 \%$ Adição em relação ao cimento \\
\hline
\end{tabular}

Os ensaios de resistência à compressão, módulo de elasticidade dinâmico, velocidade de propagação da onda ultrassônica, ocorreram aos 90 dias, e, os ensaios de carbonatação e cloretos solúveis, ocorreram aos 300 dias. Foram moldados para cada amostra estudada 12 réplicas para as propriedades mecânicas e para as propriedades relacionadas com a durabilidade (carbonatação e cloretos) foram moldados 3 réplicas de cada amostra por ensaio. Determinou-se o módulo de elasticidade dinâmico através da equação 1. Portanto, Ed, é o módulo de elasticidade dinâmico; V, velocidade de propagação da onda $(\mathrm{mm} / \mu \mathrm{s}) ; \rho$, densidade de massa aparente $\left(\mathrm{kg} / \mathrm{m}^{3}\right) ; \mu$, coeficiente de poisson (para argamassas, em torno de 0,20$)$.

$$
\mathrm{Ed}=\mathrm{v}^{2} \cdot \rho \cdot[(1+\mu) \cdot(1-2 \cdot \mu)] /(1-\mu)
$$

Para determinação da carbonatação seguiu-se o procedimento CPC - 18, Measurement of hardened concrete carbonation depth, (RILEM, 1988). Após a submissão dos corpos de prova ao ataque de $\mathrm{CO}_{2}$ em torno de $(66+/-5) \%$; $(25+/-3)^{\circ} \mathrm{C}$, verificou-se de forma visual, as profundidades de carbonatação após a aspersão da solução de $1 \%$ de fenolftaleína, $70 \%$ de álcool etílico e $29 \%$ de água destilada, com pH teórico de 9,5 a $25^{\circ} \mathrm{C}$, ficando vermelho carmim à argamassa não carbonatada e incolor a carbonatada. Analisaram-se 3 réplicas nas seguintes condições: condição (a): maturação em laboratório de 1 mês (câmara úmida), acrescido de 9 meses em sala fechada totalizando 10 meses; condição (b): condição (a) acrescido de maturação na câmara de carbonatação por 24 horas; condição (c): condição (a) acrescido de 72 horas de exposição em câmara (Figura 6).

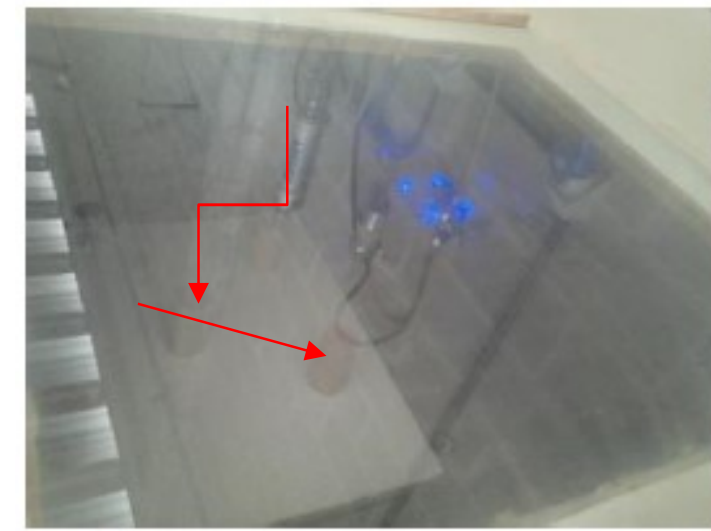

(a)

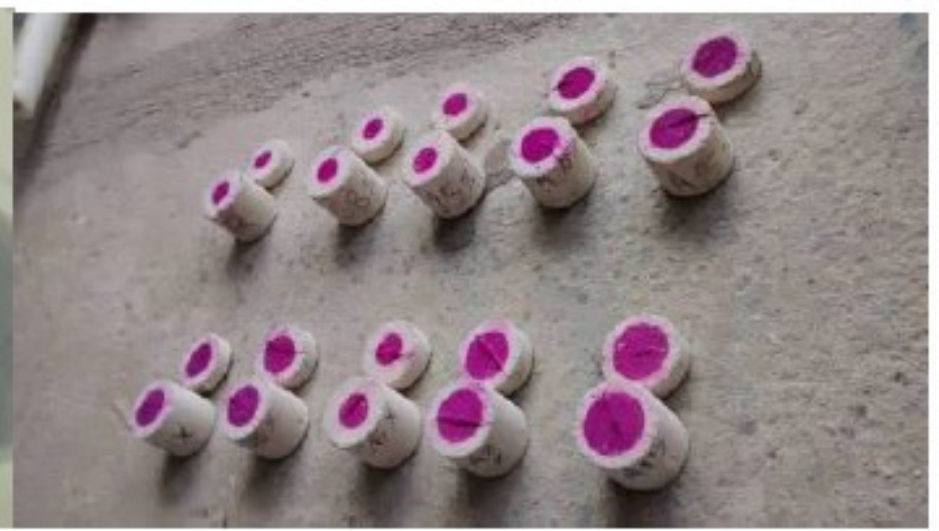

(b)

Figura 6: Corpos de prova de argamassas: (a) CP's na câmara de carbonatação (seta vermelha); (b) após a retirada da câmara com aspersão da solução de fenolftaleína 
Para análise de cloretos livres, amostras de argamassa foram submetidas à câmara de cloretos por 192 horas, a uma umidade de $(95+/-4) \%$, teor de cloreto $\mathrm{PA}$ de $5 \%$ em relação à água destilada, e uma temperatura de $(55+/-5)^{\circ} \mathrm{C}$.

Vale salientar que, esta operação teve uma injeção de pressão de ar comprimido de 1 bar para formação de salt spray. O período foi estimado tomando-se por base o tempo especificado pelo fabricante para outros materiais e pela alta relação água/cimento e porosidade das argamassas quando comparado com concretos.

Após a aspersão de solução de nitrato de prata contendo $1,7 \mathrm{~g} / 100 \mathrm{ml}$ de água deionizada, verificou-se a presença de cloretos livre, na medida em que foi identificada uma cor prateada indicativa de presença de cloretos, como ilustra a Figura 7 ("a" e "b"). Em seguida, realizaram-se coletas das amostras maturadas para análise do teor de cloretos em relação ao cimento em laboratório específico.

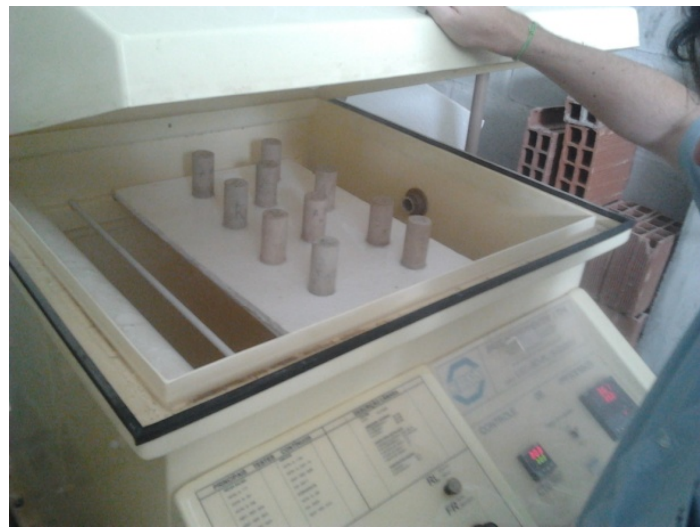

Figura 7 (a): Corpos de prova no interior da câmara de cloretos

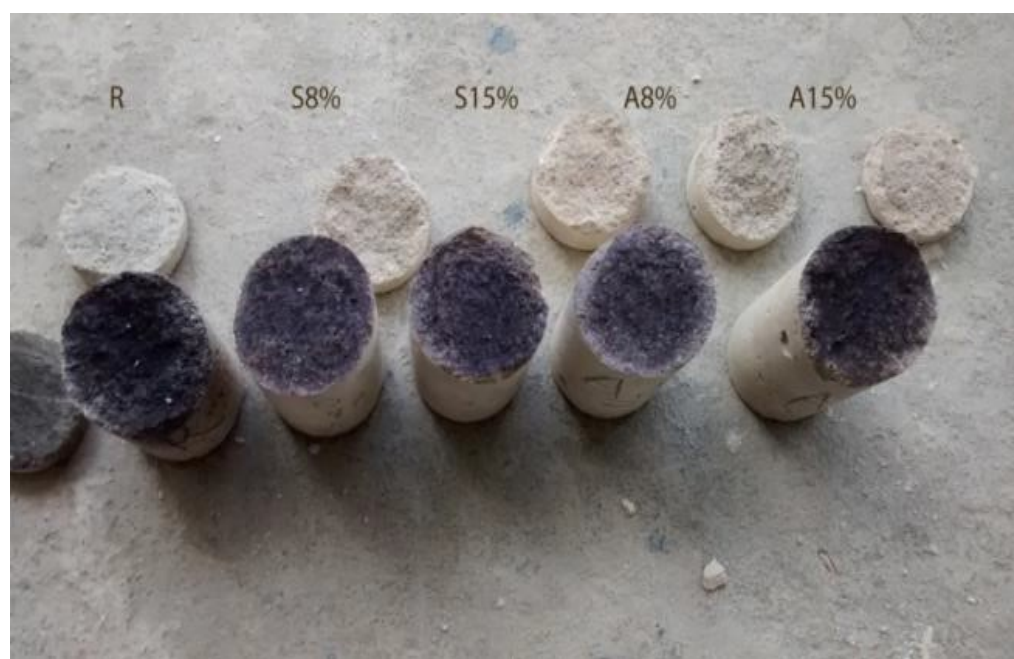

Figura 7 (b): Corpos de prova após maturação à câmara de cloretos com aspersão de nitrato de prata

\section{RESULTADOS E DISCUSSÕES}

\subsection{Resistência à compressão}

Verificou-se no gráfico exposto na Figura 8, que a amostra com traço forte e adição pura de $15 \%$ de metacaulim apresentou maior resultado mecânico, por outro lado, a amostra com traço médio e substituição de $8 \%$ de parte do cimento apresentou o menor de todos os resultados.

Observa-se também que há uma tendência linear crescente mais acentuada para o traço forte. Portanto, devido às reações entre a Portlandita e o metacaulim, responsáveis pela produção de C-S-H (composto responsável pela resistência da matriz cimentícia), observa-se que as reações pozolânicas são mais suscetíveis com teor de cimento. 


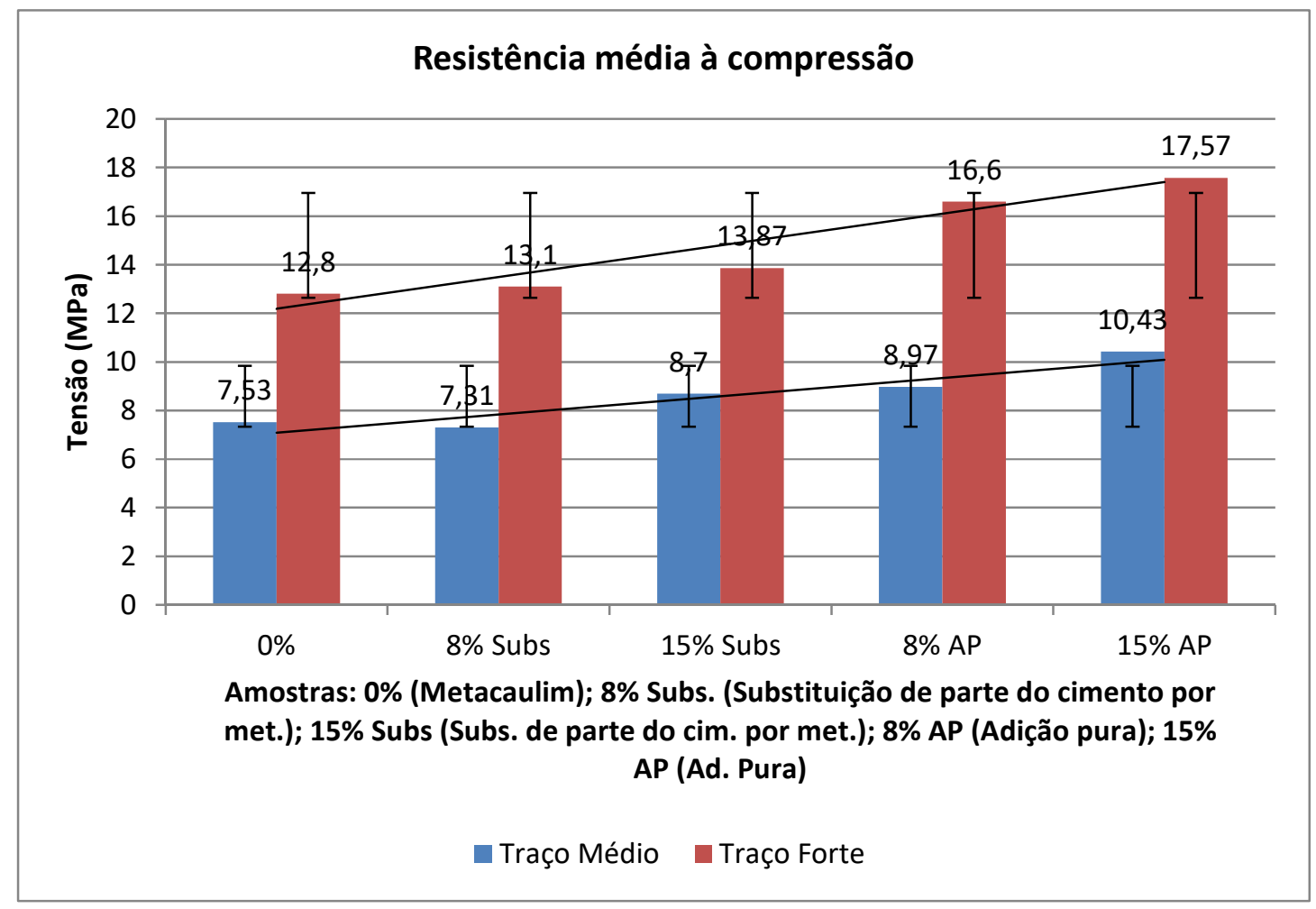

Figura 8: Resistência à compressão das argamassas (linha de tendência linear e barras de erros com desvio padrão)

\subsection{Módulo de elasticidade dinâmico}

Verificou-se na Figura 9 que as amostras com adição pura tiveram resultados superiores quando comparados com amostras sem adição e com adição por substituição de parte de cimento. A amostra com traço forte e adição pura de $15 \%$ de metacaulim apresentou o maior resultado na análise, além de que é possível verificar uma linha de tendência linear crescente em sentido aos traços mais fortes e com adição pura. Assim, observa-se que a metacaulim propicia um maior empacotamento na mistura.

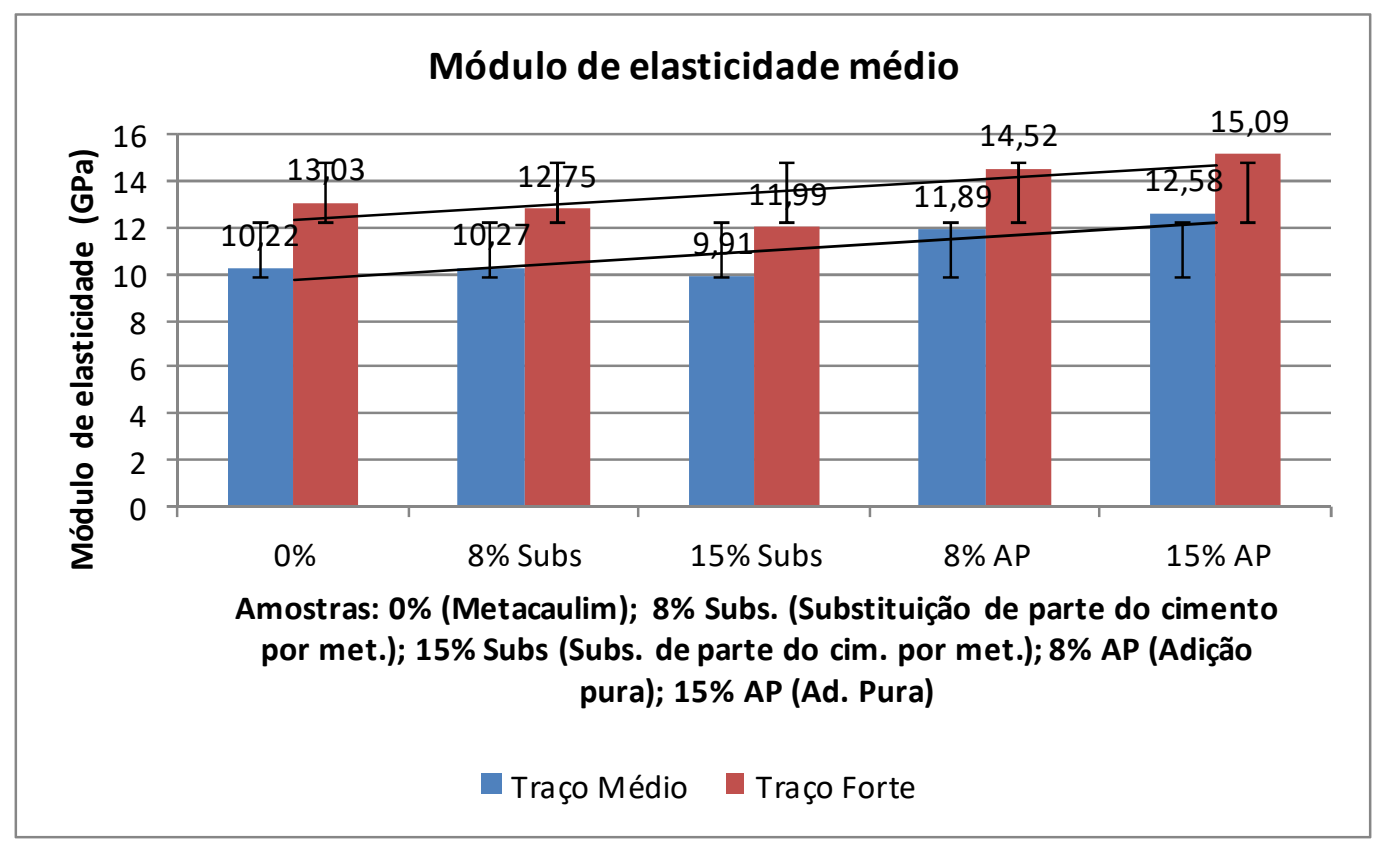

Figura 9: Módulo de elasticidade dinâmico (linhas de tendência linear e barras de erros com desvio padrão) 


\subsection{Velocidade de propagação da onda ultrassônica}

As amostras com traço forte e adição pura de $15 \%$ apresentaram resultados maiores em relação às demais amostras (Figura 10).

De acordo com WhiteHurst (1966) apud Rodrigues (2003), pode-se classificar a velocidade da onda de ultrassom nas argamassas conforme Tabela 6.

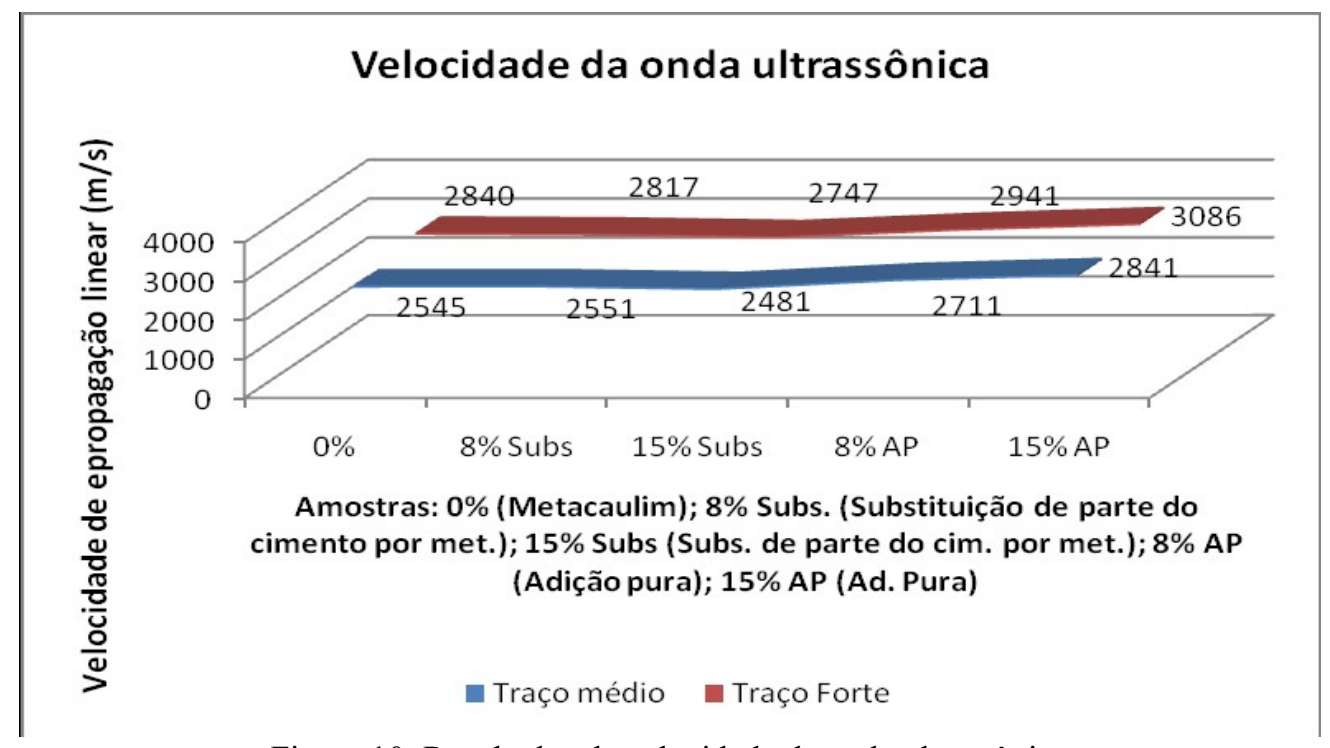

Figura 10: Resultados da velocidade de onda ultrassônica

Tabela 6 - Classificação da velocidade ultrassônica em compósitos cimentícios (WHITEHURST, 1966 apud RODRIGUES, 2003)

\begin{tabular}{|c|c|}
\hline Velocidade de propagação linear $(\mathbf{m} / \mathbf{s})$ & Classificação \\
\hline$>\mathbf{4 5 0 0}$ & Excelente \\
\hline $\mathbf{3 5 0 0}$ a 4500 & Ótimo \\
\hline $\mathbf{3 0 0 0}$ a 3500 & Bom \\
\hline $\mathbf{2 0 0 0}$ a 3000 & Regular \\
\hline$<\mathbf{2 0 0 0}$ & Ruim \\
\hline
\end{tabular}

Portanto, verifica-se que a argamassa com traço forte e adição de 15\% de metacaulim pode ser classificada como "bom" segundo WhiteHurst (1966) apud Rodrigues (2003), sendo a amostra com maior densificação.

\subsection{Carbonatação}

Analisando o traço médio, verifica-se que as amostras com $15 \%$ de adição (sem retirar parte do cimento), apresentou melhor desempenho dentre as amostras com adição de metacaulim (Figura 11).

Não obstante, no traço forte, a amostra com adição de 15\% (sem retirar parte do cimento) também apresentou resultados melhores que no traço médio, de acordo com o gráfico da Figura 12.

Entretanto, amostras com substituição de parte do cimento tiveram resultados pouco satisfatórios quando comparado com a amostra sem adição.

Portanto, não se pode desconsiderar a governabilidade do cimento, donde substituir parte do cimento poderá incrementar propriedades mecânicas, mas não necessariamente a durabilidade. 


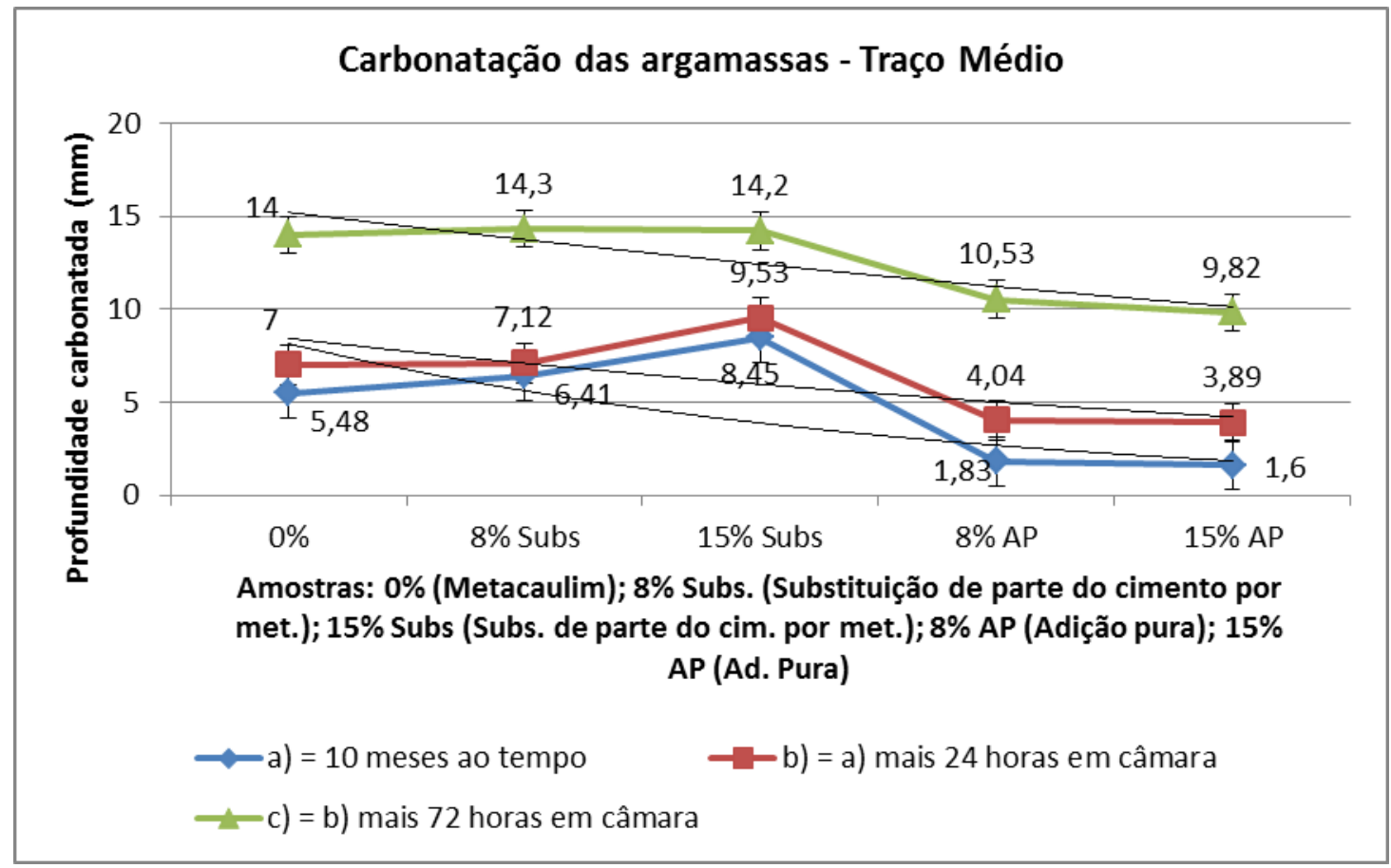

Figura 11: Curvas das três condições de maturação para carbonatação das argamassas de traço médio (linhas de tendência exponencial e barras com erros padrão)

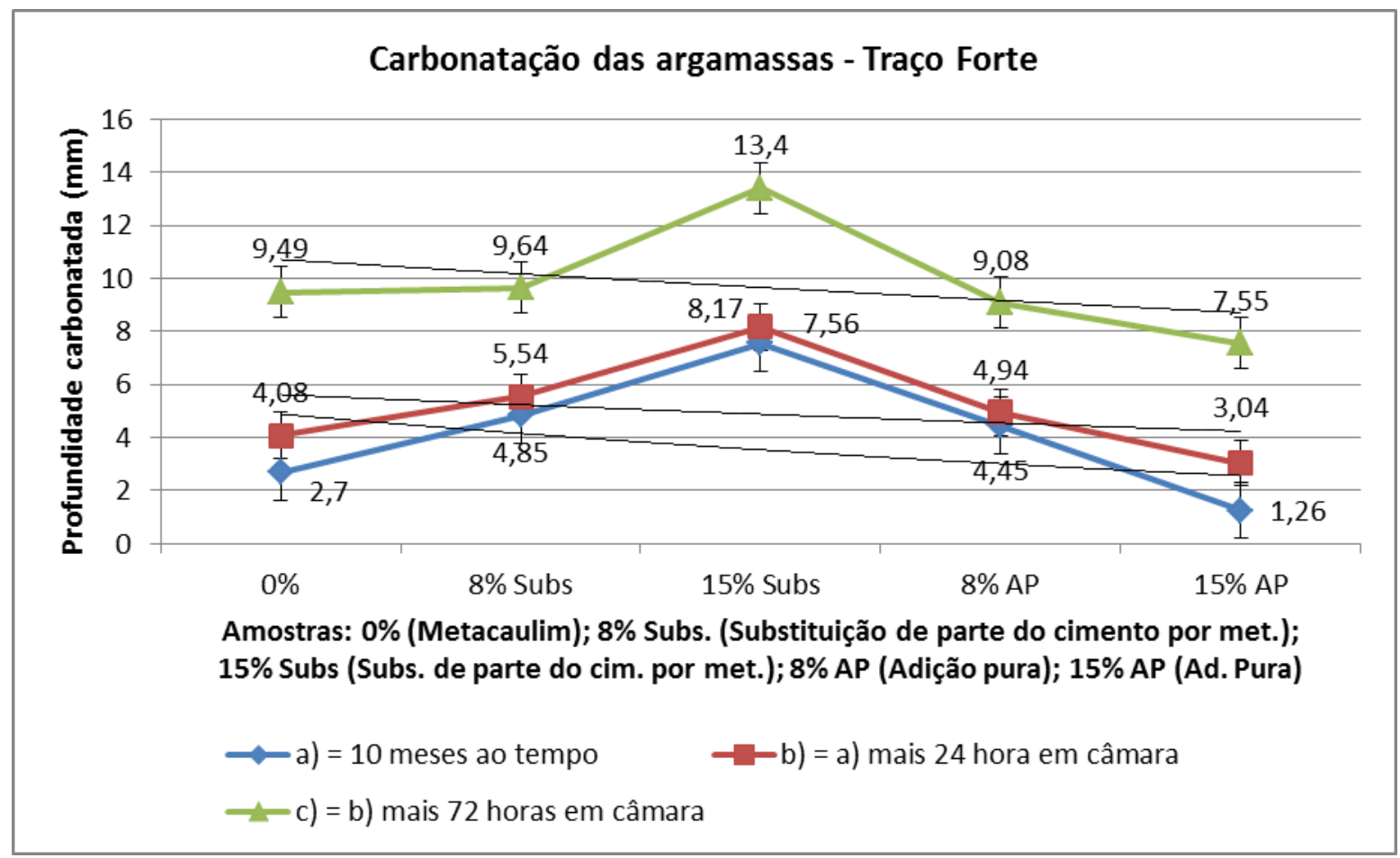

Figura 12: Curva das três condições de maturação para a carbonatação das argamassas de traço forte médio (linhas de tendência exponencial e barras com erros padrão)

Medeiros (2002) sugere classificação para as argamassas quanto à profundidade de carbonatação para as condições de $5 \% \mathrm{CO}_{2}, 25^{\circ} \mathrm{C}$ e $60 \%$ de umidade (aos 91 dias): - baixa $<5 \mathrm{~mm}$; - média entre 5 e $15 \mathrm{~mm}$; - alta $>15 \mathrm{~mm}$.

Nessa premissa, as amostras com maturação máxima (c), ficaram classificadas como "média". Todavia, em ambos os traços (médio e forte) as amostras com substituição de parte do cimento tiveram desempenho com tendência pífia. 


\subsection{Cloretos}

Para determinar o teor de cloretos solúveis, utilizou-se o método ASTM C 1152 - Standart Method for Acid-Soluble Chloride in Mortar and concrete, em laboratório específico por titulação potenciométrica usando eletrodo seletivo para cloretos. A Figura 13 ilustra os teores de cloretos nos traços estudados.

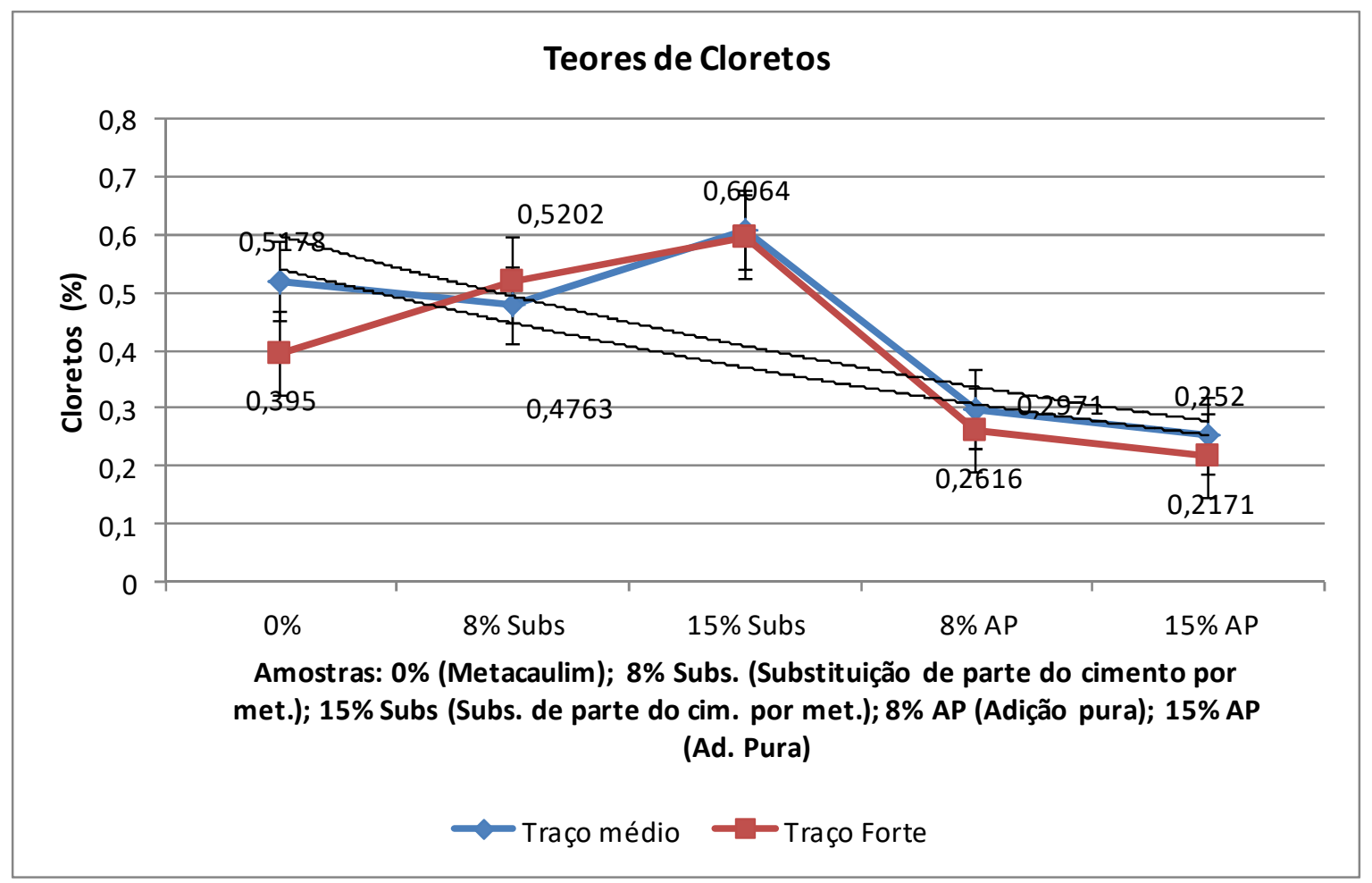

Figura 13: Teores de cloretos (Média com linhas de tendência exponencial e barras com erros padrão)

Em geral, amostras com substituição de parte do cimento apresentaram as maiores concentrações de cloretos livres em ambos os traços. Em contrapartida, as amostras com 15\% de metacaulim por adição tiveram desempenhos melhores em ambos os traços (menores concentrações de cloretos livres), principalmente no traço forte.

\section{CONCLUSÃO}

Os resultados mostraram que sob as mesmas hipóteses da metodologia estabelecida nessa pesquisa, os ensaios referentes à durabilidade mostraram que a amostra com traço "forte" e 15\% de adição pura de metacaulim, sobressaiu diante as demais amostras, de tal forma que se poderá inferir, a saber:

(a) maior resistência à compressão e módulo de elasticidade, indicando menor porosidade;

(b) maior velocidade da onda ultrassônica, sendo classificada como "bom" segundo literatura, denotando satisfatória densificação do material;

(c) menor espessura carbonatada, classificada como "média" (considerando o nível de profundidade de carbonatação) de acordo com a literatura, configurando interessante condição de proteção em centros urbanos;

(d) menor teor de cloretos solúveis, significando natureza importante para regiões marinhas.

Portanto, é possível considerar que as adições minerais nas argamassas, pode ser uma significativa ação objetivando a mitigação de manifestações patológicas seja em fachadas ou em alvenaria estrutural, uma vez que incrementa as propriedades mecânicas e as relacionadas com a durabilidade.

\section{REFERÊNCIAS}

AMERICAN SOCIETY FOR TESTING AND MATERIALS. ASTM C 1152 - Standard Test Method for AcidSoluble Chloride in Mortar and Concrete, 2012. 
ASSOCIAÇÃO BRASILEIRA DE NORMAS TÉCNICAS. NBR 8802 - Concreto endurecido - Determinação da velocidade de onda ultrassônica. Rio de Janeiro, 2013.

ASSOCIAÇÃO BRASILEIRA DE NORMAS TÉCNICAS. NBR 12653 - Materiais Pozolânicos - Requisitos. Rio de Janeiro, 2015.

\section{ASSOCIAÇÃO BRASILEIRA DE NORMAS TÉCNICAS. NBR 13279 - Argamassa para assentamento e} revestimento de paredes e tetos - Determinação da resistência à compressão. Rio de Janeiro, 2005.

CHASE, G.W. Investigations of the Interface between Brick and Mortar. The Masonry Society Journal, Vol. 3, 1985.

HELENE, P. R. L.; MEDEIROS, M. H. F. Estudo da Influência do metacaulim HP como adição de alta eficiência em concretos de cimento Portland. São Paulo: Escola Politécnica da Universidade de São Paulo. Maio, 2004.

LACERDA, C. S.; HELENE, P. R. L. A durabilidade de concretos de alto desempenho com metacaulim frente à penetração de íons cloreto. In: SEMENGO Seminário e Workshop em Engenharia Oceânica, 2004, Rio Grande. SEMENGO 2004.

LACERDA, C. S.; HELENE, P. R. L. Estudo da influência da substituição de cimento Portland por metacaulim em concretos. Boletim Técnico da Escola Politécnica da Universidade de São Paulo, São Paulo, 2005.

MEDEIROS, M.H.F. Estruturas de concreto com corrosão de armaduras por carbonatação: Comparação de argamassas de reparo quanto à proteção do aço. Dissertação (mestrado em Engenharia Civil) - Escola politécnica da USP. São Paulo, 2002.

MEDINA, Engler Apaza. Pozolanicidade do metacaulim em sistemas binário com cimento Portland e hidróxido de cálcio. Dissertação (Mestrado) - Escola Politécnica da Universidade de São Paulo. São Paulo, 2011.

MEHTA, P. K.; MONTEIRO, P.J.M. Concreto: microestrutura, propriedades e materiais. IBRACON. São Paulo, 2008.

MOTA, J.M.F. Reforço de alvenaria Resistente com Argamassa Armada e Adição de Metacaulim. Tese de Doutorado. UFPE. Recife, 2015.

MOTA, J.M.F.; OLIVEIRA, R.A.; CARNEIRO A.M. Durabilidade de argamassas com adição de metacaulim para reforço de alvenaria. Revista Matéria, v. 21, n. 4, pp. 1105 - 1116, 2016.

MOTA, J.M.F; OLIVEIRA, R.A.; SILVA, A.C.; FEITOSA, A.G.; SANTOS, W.W.; SIMÃO, D.W.G. Influência da adição de metacaulim nas propriedades de argamassas inorgânicas. VI CINPAR. Córdoba, 2010.

ROCHA, G. G. N. Caracterização microestrutural do metacaulim de alta reatividade. Belo Horizonte, 2005. Dissertação (Mestrado) - Universidade Federal de Minas Gerais.

RODRIGUES, G.S.S. Módulo de deformação estático do concreto pelo método ultrassônico: estudo da correlação e fatores influentes. 2003. 187p. Dissertação (Mestrado em Engenharia Civil) - Escola de Engenharia Civil, Universidade Federal. Goiânia, 2003.

SILVA, V. S.; LIBORIO, J. B. L. Avaliação do efeito da sílica extraída da casca do arroz na aderência de argamassas e chapiscos. In: V Simpósio Brasileiro de Tecnologia de argamassas. São Paulo, 2003.

SIlva, F. J.; MOTA, J. M. F.; GAlVÃO, S. P. Ação da Pozolana Metacaulim em Matriz Cimentícia. IBRACON. Gramado, 2013.

SOUZA, P.S.L., Verificação da influência do uso de metacaulim de alta reatividade nas propriedades mecânicas do concreto de alta resistência, Tese de D.Sc., UFRGS. Porto Alegre, Brasil, 2003.

WHITEHURST, E. A., Evaluation of concrete properties from sonic tests. Detroit: American Concrete Institute, 1966. 